\title{
Some Issues in the Design of Agricultural Decision Support Systems
}

\author{
P. G. Cox \\ Socioeconomics and Policy Division, International Crops Research Institute for the \\ Semi-Arid Tropics (ICRISAT), Patancheru, Andhra Pradesh 502 324, India
}

(Received 6 June 1995; accepted 20 October 1995)

\begin{abstract}
$A B S T R A C T$
The development of crop and soil process models, and their incorporation into decision support systems (DSSs) for the practical management of agricultural production, have made a significant contribution to the focus and integration of research by agricultural scientists. However, such DSSs should not necessarily be used as vehicles for communicating with other groups, such as farmers, with a view to effecting directed change in their behaviour. Other, sometimes more effective and efficient (and often more enjoyable and elegant) models are available.

The historical, and seemingly unwarranted, escalation of organisational commitment to the provision of agricultural DSSs appears to have been based on a fundamental category mistake of confusing process models (for professional research) with model-based DSSs (intended as a guide to practical action). This escalation of commitment has had substantial implications for the design and implementation of both modelling and DSS projects, and has precluded the development of distinctive criteria for evaluating DSS success. Design issues for DSSs include: the need for an analytical phase in DSS development to deconstruct professional models; resolution, validation and appropriateness in relation to intended purpose, in order to avoid over-engineered solutions; its contribution to communication practice; and the role of professional responsibility. The SIRATAC cotton pest management system, used in Australia between 1980 and 1993, is presented as a case study. Copyright (C) 1996 Published by Elsevier Science Ltd
\end{abstract}

\section{INTRODUCTION}

There is increasing concern by $R \& D$ funding bodies that investment in the development of decision support systems (DSSs) to improve agricultural 
practice has been largely wasted because these products have not been widely taken up by producers (LWRRDC, 1993). The impact of the software on better decisions, greater competitiveness, or improved sustainability is only rarely documented, and there have been few attempts to quantify its effects.

Interest in building agricultural DSSs has come primarily from the professional research community, although in several cases (including the original SIRATAC program, see below) there has been pressure from industry to bring the technology to market as quickly as possible. The pressure has arisen from the increasing demands for accountability in publicly-funded agricultural $R \& D$ programmes, which need a tangible product to indicate that something has been done. Further pressure has come from the move towards commercialisation of publicly-funded $R \& D$, which is taken to mean the production of information packages which can be sold. In Australia, this has coincided with the redeployment of traditional public sector extension officers, and the rise of regional information centres as (at lcast a partial) substitutc for 'onc on one' extension (Hanger \& Vock, 1993).

There are reasons for supposing that the expectation that farmers could usefully exploit DSS technology to improve their own practice is seriously flawed. First, the design and presentation of DSSs are sufficiently complex to require considerable technical support before one can operate them effectively; they frequently require monitoring data about the state of the system which it is unrealistic to expect farmers to collate; and they are based on an information platform (the computer) which few farmers currently use as a planning tool. Second, most DSSs are justified on the basis that they provide information that is useful only for the exception; they are rarely applied to improving performance in routine situations where the answer is often clear. Thus, the potential gains from using the technology are marginalised: to those people who least need assistance (because of the extent of their current skills); and to situations where the balance between costs and benefits is problematical. The issue is important because of the substantial resources currently devoted to this activity; the need to allocate increasingly scarce research resources to the development of technologies with the highest potential payoff; and the need to think as broadly as possible about how we can best use information technology to achieve the increasingly urgent goals associated with improved agricultural production and long-term sustainability in resource use.

In this paper, I suggest that the potential for using models of crop and soil processes in a direct way, and in isolation, to support routine farmlevel decision-making is problematical. The products usually cited as exemplars of this activity are, on closer examination, poorly justified. The 
process of $\mathrm{R} \& \mathrm{D}$ which gave rise to agricultural DSSs can only be judged inadequate if the criterion of its success is the wide uptake of novel information technology by farmers and graziers.

I also suggest, however, that the spinoffs of DSS development have been significant. By bringing researchers and producers together to focus on issues of concern to the industry, some progress has been made in improving the effectiveness of professional R\&D. This has often captured the energy and enthusiasm of both parties. We should question the assertion that the primary benefit of this activity was the production of DSSs intended to aid routine decision-making at farm level. The appropriate criteria of success lie in the effectiveness of the DSS development process in bringing different points of view to bear on an issue of common concern, not in the need to run process models whenever a routine decision has to be made. This change of focus emphasises participation by multiple stakeholders, expressing values, in networks for action. The outcome is, potentially at least, the improved management of agricultural production systems rather than the adoption of a decision aid. The development of distinctive criteria for evaluating success in the construction and use of crop and soil process models in agricultural R\&D, and for DSSs to support decision-making in the management of agricultural production systems, are urgently needed if we are to capitalise on the gains that we have already made.

I have not attempted a detailed description of the many model-based DSSs that are currently available (see e.g. Reynolds, 1993; Stapper, 1993). The argument is cast in general terms. The SIRATAC cotton pest management model (Hearn et al., 1981), which was used in Australia between 1980 and 1993, is presented as a case study to illustrate the argument. SIRATAC was chosen because of its familiarity; because it is still frequently cited in Australia as an example of a successful agricultural DSS; and because it was finally abandoned in 1993.

\section{POOR FIT WITII TIIE DESIGN CIIARACTERISTICS OF DSS}

The phrase 'DSS' is used increasingly in a loose sense to indicate any kind of decision aid, whether computer-based or not, and whether the problem it purports to address is more or less well structured. It has almost become synonymous with 'extension'! However, it generally excludes maps and models developed by farmers for their own use, or as part of a Participatory Rural Appraisal (Lamb, 1993), even though these are particularly powerful decision aids and would appear to be a good starting point for the development of more elaborate models if such were needed. In this 
paper, I focus on DSSs that have evolved out of, or in parallel with, process models of components of agricultural production systems.

DSSs were originally developed within an industrial or commercial context (Bennett, 1983; Sage, 1991). They were seen as a way of gaining an understanding of the implications of different ways of dealing with relatively unstructured problems, not amenable to the standard algorithms of management science. They incorporate models, databases, a query language and an interface. Turban (1993) describes an archetypal DSS. It is definitely a computer-based information system. It is often built by the people who will use it. It reflects the decision-making style of the decisionmaker. The decision-maker has control over all aspects of the decision. The time to construct a DSS is short (perhaps as short as a few days) and it can be modified easily as the problem structure changes. It is a highly interactive application for computer-literate people within a complex organisation (often hierarchical, certainly with specialised functions). It is seen as an adjunct to other procedures.

This maps poorly onto the characteristics both of agricultural DSSs and of the proposed clients of this activity. Decision-making in the routine management of broadacre dryland agricultural production systems is sufficiently well-structured for the use of standard algorithms (Cox, 1993a) and is often conceptually quite simple. Examples include decisions on the best rate of fertiliser to apply, based on estimates of nitrogen deficiency in the previous crop, or whether to plant a particular crop based on the availability of a planting opportunity at a certain time of the year. Admittedly, the outcome is often uncertain, depending, for example, on the incidence of in-crop rainfall, but this constitutes background noise to the decision problem, and does not indicate a change in model structure. There are situations where little is known (for example, the introduction of a crop new to a region) and these may provide transient demand for decision support. But these situations are already handled in other ways. In evaluating a DSS, the focus should be on its marginal contribution to achieving improved outcomes.

An agricultural DSS usually imposes a structure on a decision. This may be different from that perceived by the decision-maker (Hofstede, 1992). Indeed, 'education' of farmers is often cited by professional agriculturalists as justification for constructing a DSS, thus further confusing DSS technology with computer-aided instruction. Because DSSs are computer-based, there is poor correspondence with the decision-making style of most agricultural practitioners who, unlike professional researchers, do not generally use computers in this way. The rigidity of most agricultural DSSs precludes major re-configuration by users even if they had access to the source code and sufficient programming skills to do it. There 
is in any case a need to incorporate the output of a DSS with the many other issues not covered by the underlying process models.

Macpherson \& Grant (1989) point out that the use of simulation in policy debate is a rhetorical device. Debate is a matter of persuasive communication. Yet agricultural DSSs are usually constructed as though they described the outcome of a course of action in a way that is readily accessible and unproblematical. It is unclear whether this is due to the deliberate use by professionial agriculturalists of argument by authority (based on an inaccessible process model), or to the naivety of the system designers about the everyday practicalities of agricultural production, or to the progressive development of a novel technological metaphor based on conspicuous production (Badham, 1991).

The issue is whether professional researchers, trained in reductionist science and rewarded primarily for their contribution to better understanding, can be relied upon to specify the system boundaries in a way that reflects the constraints and opportunities faced by agricultural practitioners. The presupposition must be that they cannot. Modelling has been done in relative isolation. The focus of professional $R \& D$ has not been on how best to change client behaviour, but on the justification for a prior interest in model construction; not on how best we can solve problems of common interest and concern (whether using process models or not, to support research or directed behavioural change or conspicuous production), but on what applications we can find for our models. In some situations, there has been a deliberate attempt to change the behaviour of producers (e.g. the use of SIRATAC to encourage producers to adopt the principles of Integrated Pest Management, see below). Increasingly, however, these tools are proposed to help producers evaluate options (and make of them what they will), not to extend the adoption of a preferred practice through better understanding of the benefits and costs associated with it.

The proposed use of models in this way is a category mistake (Ryle, 1963): it conflates different categories of knowledge, and different ways of knowing. As Ryle states (p. 19): "The theoretically interesting categorymistakes are those made by people who are perfectly competent to apply concepts, at least in the situation with which they are familiar, but are still liable in their abstract thinking to allocate those concepts to logical types to which they do not belong." The management of biological production systems is only loosely analogous with the use of an automotive braking system: biological systems are characterised by stochasticity, openness and equi-finality; the speed of a car is well-controlled by balanced, progressive servo-mechanisms. The category mistake is an example of the 'fallacy of misplaced concreteness' (Whitehead, 1929; see Daly, 1991). 
Different ways of using models have been recognised in the operational research literature for many years. Thus, Ackoff \& Sasieni (1968); p. 89) state: "Models are normally thought of as instruments for selecting the best (or at least a good) course of aciion from that set of courses of action that is 'covered' by the model. However, models have another very important use that is frequently overlooked: they can be used heuristically, that is, as an instrument of discovery... Many of the most successful applications of operations research have involved the use of models to uncover possibilities not normally considered in the literature on the relevant type of theory. The value of such exploration cannot be overemphasized...in most such cases, the course of action is so obviously superior to the possibilities that were previously considered, that a model is hardly needed to justify their choice."

There is poor understanding among researchers of what an agricultural DSS does when farmers (or other practitioners - the intended clients of the DSS) use it. There is an implicit assumption that a DSS provides the best available information, and that this is sufficient justification for its development and for promoting its use. This is rarely based on a previous understanding of the problems decision-makers face; nor of how they are handling them now; nor of how this particular kind of intervention might facilitate more effective decision-making behaviour; nor of how it compares with other ways of doing things. Market research has usually only been done after the product has been released, after the developers become concerned about its low uptake (e.g. O'Keeffe, 1992) and evaluation of the intervention is done poorly, if at all (Finlay \& Wilson, 1991). Where this is attempted, the conceptual framework is weak. Indeed, it is a very hard thing to do (Adelman, 1992; Willcocks, 1994).

There is, more than ever, the need to pause and think about current levels of $R \& D$ investment in information technology to support the management of agricultural production systems. I echo the remarks of Angell \& Smithson (1990) who said: "...our message is not anti-technology per se, it is rather that decision makers must re-examine the assumptions under which systems are justified, and they must become aware of the risks inherent in the introduction of information technology and balance them against the benefits."

\section{SOME ISSUES IN THE DESIGN OF AGRICULTURAL DSS}

If as a society we are serious aboul using professional researchers and scientific knowledge to enhance a process of social change, such as changes in the way agricultural production systems are managed, in order to 
incorporate social objectives in maintaining the stock of natural resources, then the provision of information is not likely to be very effective on its own. Information is not knowledge, particularly when the information is presented in a way that is confusing, embodies a conflicting set of values, and fails to recognise the decision-making style of the client group. If we are not serious about contributing to social change, why are professional researchers so intent on constructing DSSs?

I proposc four issucs that demand considcration: the nced for an analytical phase between model construction and use in a DSS; the use of an appropriate resolution in problem definition, model validation and solution in relation to the purpose of the activity; the need for changes in communication practice between professional researchers, acting as consultants, and practitioners; and acceptance of greater professional responsibility by agricultural researchers. These issues are illustrated by the following case study.

\section{Need for an analytical phase}

Insertion of an analytical phase between the construction of a process model and the development of a DSS will often obviate the need for the development of a DSS for use by practitioners. The analytical phase will indicate the sensitivity of possible outcomes to changes in the way a system is managed, and the implications of alternative courses of action. Often, the performance of an agricultural production system will be relatively insensitive to small changes in the way things are done (Goodwin \& Wright, 1991); due to the natural homeostasis of biological systems, and the availability of opportunities to recover from management mistakes. Furthermore, uncertainty about the difference a change in behaviour will make (whether derived from uncertainty about initial conditions, or parameter estimation, or stochastic inputs, or exogenous events) will often mean that the implications of different management options cannot be distinguished. In either case, a DSS will be of little value for routine decision-making: either there are no differences between alternative actions; or we cannot distinguish them; or the differences are not important.

\section{Resolution, validation and purpose}

The appropriate resolution of process models of agricultural production systems is rarely considered by system designers. Validation is usually bascd on a plot of simulated versus actual outcomes over a wide range of experimental treatments. This procedure is inadequate if the issue is at a finer scale, or in a commercial setting where the noise is much higher. 
I suggest an optical analogy: it is possible to build a microscope that achieves very high magnification, but its resolution is limited by the wavelength of the incident radiation used in the apparatus. I suspect that the process models on which agricultural DSSs are built have inadequate resolution to distinguish much of what interests practitioners. The result is empty magnification. There is a mismatch between the resolution of the model and its intended purpose.

Problems with the validation of numerical models in the earth sciences are increasingly recognised. Konikow \& Bredehoeft (1992) suggest that the terms validation and verification are misleading, and their use in groundwater science should be abandoned in favour of more meaningful model-assessment descriptors. Validation and verification are not generic activities, but should be designed in relation to the intended use of each model; as the use changes, the criteria for assessing whether a model works satisfactorily, and contributes to the analysis, also change. Oreskes et al. (1994) point out that validation and verification of numerical models of natural systems are impossible because such systems are never closed and because model results are always non-unique. Models can only be evaluated in relative terms; their primary value is heuristic.

The arguments of these authors are not that we cannot build models of open systems (we do this quite happily), only that such models will not have a unique, or even widely-accepted, solution. A process model is a proposition about how some part of the world might function rather than a description of the way it does function, which can often be better handled using empirical models. Process simulation can assist in the design of heuristics for the routine management of agricultural production. They are not a replacement for those heuristics. Nor do they replace the need to negotiate those heuristics further with relevant stakeholders so they are adequately contextualised. The need is for models with a degree of resolution, appropriately validated, that cope adequately with the emergent properties of systems in the context of substantial background noise. This argues for simpler, not more complex, models if the interpretation of model output is to be done by people other than those who built the models. Enough complexity emerges through interaction of the problem owners with the problem situation. Current DSS technology, intended to support routine decision-making, is over-engineered.

\section{Communication practice}

The substitution of software products as a proxy for direct communication resembles traditional extension; an intermediary is inserted between the communicating parties. The DSS, like extension, filters communication 
both ways. Use of a product as a substitute for communication stifles it. Participation and communication together provide a more appropriate focus. This change in perspective is captured, to an extent, by the progress of the human-centred systems movement (Checkland, 1981). Computersupported cooperative work (Baecker, 1993) is an emerging metaphor. But this has yet to permeate to any significant extent the design of agricultural DSSs. There are things to do with models other than build agricultural DSSs that few people want, fewer will use, and where the payoff from research is correspondingly restricted.

\section{Professional responsibility}

The language of crop and soil process models, and the management of the assumptions on which they are based, are the tools of professional science. They can be a powerful way to generate insights, but this requires craft skills both to use them in a sensible way and to evaluate suggested outcomes critically. Professional researchers are valued in society because they have these craft skills. Clients, in general, use a different set of tools for different purposes. Not to do what it does best, or at least where it has a comparative advantage, by relegating this to a digital assistant, is an abdication of responsibility by professional science. We need to be clear to whom we, as professional researchers, are accountable. This will mean much greater attention to issues of comparative performance with other model formulations (including, and especially, those of practitioners) and the criteria by which the success of interventions of different kinds are established at the margin.

\section{SIRATAC - A CASE STUDY}

SIRATAC, an acronym for CSIRO $\mathrm{O}^{1}$ and the New South Wales Department of $A$ griculture $T A$ ctics for growing Cotton, was a dial-up computerbased tactical crop management system for irrigated cotton. It evolved from a prototype constructed by Room (1979) with the purpose of synthesising research results into a practical integrated management system which made best use of the information available. The apparent success of SIRATAC in the early 1980 s (with $25 \%$ adoption by area) has provided a benchmark against which other DSSs have been judged.

SIRATAC was developed initially to help growers make day-to-day decisions about the use of insecticides in irrigated cotton. Cotton cannot be

${ }^{1}$ CSIRO is the Commonwealth Scientific and Industrial Research Organisation 
grown commercially in Australia without chemical control of insect pests. This typically costs between A\$100 and A\$300 per hectare each year. Spraying can also result in an increased risk of resistance to insecticides developing in pest populations, more frequent outbreaks of secondary pests, and heightened public concern about actual and perceived environmental pollution with chemical residues.

SIRATAC tried to reduce the risks associated with pesticide use by adopting the following principles of Integrated Pest Management (IPM): (i) making maximum use of the natural mortality of cotton pests; (ii) whenever possible using 'soft' sprays which are not persistent, having a minimal effect on beneficial insects, and which kill a narrow range of insects; (iii) utilising the natural fruiting habit of the cotton plant which produces two to three times more fruit than it can mature and which can compensate to a degree for early insect damage by replacing fruit that is lost; and (iv) spraying only when pest numbers exceed action thresholds. Action thresholds are pest densities above which the value of the damage caused is greater than the cost of control.

The results of field experimentation with the SIRATAC system in the early 1980s excited a core group of potential users into lobbying CSIRO to commercialise the prototype as quickly as possible. They argued that commercialisation, by bringing the technology to market earlier, would focus the research effort. The researchers acquiesced in the belief that SIRATAC would be an appropriate conduit for the extension of research results. The program was intended to be a decision aid for the professional pest manager, not a computerised replacement. The SIRATAC system has been described in outline at various stages in its development (Room, 1979; Hearn et al., 1981; Brook \& Hearn, 1983, 1990; Ives et al., 1984; Hearn, 1987; Ives \& Hearn, 1987; Macadam, 1988; Hearn \& Brook, 1989).

The area managed using SIRATAC increased steadily during the early 1980s. The demand for a 10-fold expansion in 1981/82 was beyond both the resources and the terms of reference of research. The three organisations that ginned and marketed the crop in New South Wales and Queensland set up a company, SIRATAC Ltd, to make SIRATAC available on a commercial basis to all cotton growers (Brook \& Hearn, 1983).

Although SIRATAC Ltd was achieving market success, it became apparent by 1985 that a ceiling in the adoption of the technology had been reached at about $25 \%$ (by area) of the industry. This fell far short of the $60 \%$ lcvel of acceptance envisaged by the architects of SIRATAC Ltd. Consequently, the company only just remained solvent (with a peak annual revenue of about $\mathrm{A} \$ 0.5 \mathrm{~m}$ ) for most of its life. The SIRATAC 
technology was 'leaking over the fence' to non-SIRATAC managed properties. Savings in insecticide applications became harder to demonstrate as pest management improved in the industry. Commercial viability depended on continued innovation. The SIRATAC Plus project was a response to this.

Researchers were interested in improving the quality of the decisions produced by the SIRATAC program and in providing an explanation capability to support those decisions. Re-implementation of the system would reduce the burden of maintaining the FORTRAN code which by this time had become highly convoluted. The CSIRO Division of Information Technology (DIT) persuaded the cotton researchers to re-implement the SIRATAC system using an expert system language (OPS5), a relational database, a data dictionary and a complete re-specification of the FORTRAN models (Coulomb et al., 1988). The original interface system was to be written in RALLY, a fourth generation screen language for DEC VT100 terminals and emulators. During field trials with RALLY, it became apparent that the VAX minicomputers being used by SIRATAC could not provide an adequate response time for interactive use. A front-end data entry system was proposed to provide a fast windowed environment compatible with modern microcomputer interfaces.

The SIRATAC Plus re-implementation project ran for over 4 years and was grossly over-budget and behind schedule for its entire life. The eventual prototype that was delivered by DIT was vastly larger and more complicated than the original SIRATAC FORTRAN system, but provided less biological and management functionality. The response time was 60 times slower, and the company could not afford enough mainframe power to run the system. The microcomputer front-end was cumbersome and tedious. In 1990, the project was abandoned. The central minicomputer route was an evolutionary dead-end. The failure to provide an enhancement and replacement for SIRATAC further contributed to SIRATAC Ltd's demise.

DIT had seen SIRATAC Plus as an opportunity to develop an industry demonstration of systems engineering. It was even more complex in its inception than the original SIRATAC code (partly in relation to the specification of its expert system, partly to the requirement to handle a graphical user interface down a telephone line to access a central database. and partly in its use of a relational database and a data dictionary). This emphasis derived from a lack of congruence between the goals of the system engineers and those of the biological researchers. The researchers had unwittingly allowed SIRATAC to be hijacked. The opportunity to simplify the technology was not taken. This was a conceptual problem which underpinned both SIRATAC Plus and the original SIRATAC model. 
In 1986, a research team from the University of Western Sydney (previously Hawkesbury Agricultural College) conducted a qualitative in-depth analysis of the attitudes to and perceptions of SIRATAC and SIRATAC Ltd within the Australian cotton industry (Macadam et al., 1990). This was precipitated by increasing unease about the role of SIRATAC and SIRATAC Ltd. Some of their findings related to the design of the SIRATAC technology.

Although SIRATAC users might have saved up to two sprays compared with non-users when the methodology was first introduced in the early 1980s, this difference did not persist. The justification for continuing to support a computerised pest management system was far from clear when similar patterns of pesticide use could be generated without using a computer at all. Some growers disagreed with the types and timing of chemicals recommended by SIRATAC: expensive chemicals were suggested when they felt that a cheaper one would do; and SIRATAC did not recommend sprays as often as growers felt comfortable with. Thus, sprays were selected on the basis of criteria which were not congruent with those of growers. In practice, the early season Heliothis thresholds used by SIRATAC to precipitate a spray application were progressively reduced. Nevertheless, many growers felt that they were continually overriding the system and subsequently abandoned it.

Some growers believed that the use of dynamic (i.e. high early season) thresholds produced late crops. They rated production of an early maturing crop as a high priority. Subsequent work by Cox et al. (1991), using the SIRATAC models, confirmed that placing a high value on earliness would significantly reduce optimal early season Heliothis thresholds. Furthermore, the underlying simulation models may not have been accurately tracking the compensation of the cotton crop in response to early insect damage (Brook et al., 1992a,b,c). SIRATAC abandoned dynamic thresholds for Heliothis in Phase 2 of crop development (i.e. after flower initiation) during the $1988 / 89$ cotton season.

Despite the fact that the area managed with SIRATAC was at a historical high, SIRATAC Ltd went into voluntary liquidation in June 1989 in response to a projected declining market share under existing pricing arrangements, industry political problems and projected cash flow difficulties. A sizeable minority of growers still wanted to use the SIRATAC computer program. An informal SIRATAC User Group (SUG) was formed to run the program for a few more seasons until a microcomputer replacement was available. This arrangement operated successfully for four seasons (1989/ 90 until 1992/93). Field support of the system was no longer available and a research moratorium on SIRATAC development meant that only minor changes to the code were made. The User Group ceased operation in 1993. 
The failure of the SIRATAC Plus reimplementation prompted a parallel activity at the CSIRO Cotton Research Unit. The goal was to achieve similar functionality on a microcomputer. A prototype product, entomoLOGIC, was written in Hypercard for an Apple Macintosh. entomoLOGIC used production rules to capture the knowledge in SIRATAC. Deconstruction of the SIRATAC code generated about 60 rules governing pesticide use. This number appeared too small to justify the use of expert systems technology. In fact, the number of rules that could be fired at any one time was substantially less than 60 because only certain chemicals could be used at certain times of the year (as defined by the Insecticide Resistance Management Strategy, see below). In field trials, entomoLOGIC successfully mimicked SIRATAC spray recommendations except in situations where the size of the pest population was projected forward by the insect population model in SIRATAC. In practice, these situations could have been handled by adjustments to the rules rather than to projected pest numbers.

The issue was not about the most effective way to manipulate a complex knowledge base, but had much more to do with the mundane activities of routine record keeping. The prototype of entomoLOGIC dispensed with both the crop model (which no longer contributed to changes in decisionmaking after dynamic thresholds were abandoned) and insect development models (on the basis that this could be captured adequately using modifications to the rule base). Nevertheless, when entomoLOGIC was released in 1993, it did incorporate process models (McKewen et al., 1994).

Considerable loyalty to SIRATAC, and the people involved, persists. This makes criticism difficult. The balance between loyalty (reinforcing the status quo), exit (walking away from it because it seems too difficult, or too costly, to change) and voice (speaking out with a view to changing the situation) (Hirschmann, 1970) is always a difficult judgement call. Participants in the SIRATAC story still find this hard. Yet there is much to learn from their experience.

\section{DISCUSSION}

\section{The ambiguous record of modelling $R \& D$}

Modelling of agricultural production and land use systems (at crop, farm and regional levels, and incorporating both ecological and economic perspectives) has become more complex, sophisticated and accessible in the last 15 years since the microcomputer revolution. Simulation modelling is 
increasingly seen as essential for professional research in ecological economics (Maxwell \& Randall, 1989; Costanza et al., 1993). Several reviews over that period (Monteith, 1981; Bennett \& Macpherson, 1985; Seligman, 1990; Philip, 1991), however, have questioned the value of such sophisticated crop and soil process models as a means of bringing about change in producers' behaviour. According to Seligman, crop modelling has not yet matured to a stage where its function and utility are no longer open to question. We have still not addressed the concerns so eloquently expressed by Bennett $\&$ Macpherson (op. cit.) 10 years ago. The progressive incorporation of these models into decision support systems for practical application in the routine management of agricultural production only serves to emphasise this blind spot. Thus, Hamilton et al. (1991) propose that computer-based decision aids have not been oversold, just underdeveloped. Whereas Stapper (1993) asks whether these are applications in search of users, rather than a response to users in search of solutions. The answer is somewhere between these extremes.

\section{The assumptions of DSS}

Current agricultural DSSs are based on the notion that the performance of agricultural production systems is limited by a shortage of information of the kind that professional science can provide, and/or by defects in the decision-making processes of resource management practitioners. I suggest that there is little evidence to support either of these two suppositions. Practitioners often do not need the detailed process understanding that researchers value in order to operate effectively in the world. Indeed, this notion of a DSS is at odds with the standard concept of a DSS in non-agricultural situations: as a computer-based information system that allows advantage to be taken of data resources, and means of processing data, that are too computationally demanding to be undertaken manually; and to provide a structure to help the user to work systematically through an issue. DSS technology, because of its complexity and lack of transparency, can hide important conflicts that need to be resolved on other than technological grounds. There may only be a very limited subset of agricultural decision problems where DSS technology can usefully contribute to improvements in routine decision-making.

That something has clearly gone wrong in the development and application of simulation models of crop and soil processes to address important issues in the management of agricultural production has been noted in several thesis studies (e.g. Hofstede, 1992; Leeuwis, 1993; Schmidt, 1994). Hofstede calls for researchers to have 'modesty in modelling'. 


\section{DSS as a social process}

The situations of which I am aware where DSSs have had some impact at farm level have certain characteristics: either they are embedded in a much richer cultural process of interaction between professional agriculturalists and farmers, or they are generic tools. An example of the first includes MIDAS (Kingwell \& Pannell, 1986), a whole-farm linear programming model which has been widely used in Western Australia in group extension activities. An example of the second includes the success of workshops on the use of accounting packages and spreadsheets by the Queensland Department of Primary Industries in which farmers build their own models. This echoes the experience of Collins (1990) who points out the need to embed expert systems (or computer technology of any kind, including calculators) into a social process.

The early success of SIRATAC can be attributed to these concomitant social processes: the consultancy efforts of SIRATAC Ltd (a growersupported organisation set up to market the technology) provided substantial industry ownership of the technology. The success of SUG following the collapse of SIRATAC Ltd also supports this idea. SIRATAC did change communication practice between professional researchers and practitioners and facilitated the introduction of IPM (Cox, 1993b). In this sense, it was a facilitating technology, despite the mismatch between model complexity and the issue of making spray recommendations. In other situations, DSS technology is accepted as an alternative to social interaction, as a replacement for constructive dialogue.

\section{Communication practice in DSS development and use}

However, even within SIRATAC, the DSS framework was set by the researchers. Inputs from producers were accepted only within the context of that framework: the argument was about the appropriate level at which thresholds should be set, and the way in which SIRATAC should be financed. Finc adjustments were being made by the computer model to the estimation of insect pest numbers that precipitated a spray decision, but little attention was paid to the value of these given the uncertainty associated with poor crop monitoring and insect scouting, and different perceptions of potential yield. SIRATAC was a decision-making system, not a decision-support system. It provided limited opportunity for a user to investigate the implications of using spray thresholds other than those recommended because part of the justification of SIRATAC was the assertion of higher thresholds than would otherwise have been used in order to restrict the development of resistance in the insect population. 
In the language of Senge's system archetypes (Senge et al., 1994), SIRATAC followed a 'Shifting the Burden' template; it diverted attention away from the real source of the problem which becomes weaker as less attention is paid to it.

\section{Evaluation}

The output utility of a modelling exercise is the key issue, but little is usually done to check that it exists or that it is worth the effort (Bennett \& Macpherson, 1985). Johnston et al. (1992) considered the payoff to the research investment in the SIRATAC pest management system. This analysis was flawed by: insufficient recognition that the same pesticide regimen was achieved by many farmers without running the SIRATAC model; the failure to distinguish the value of IPM technology (spray on threshold, and the rules associated with the Insecticide Resistance Management Strategy) from the value of the SIRATAC model used to generate specific recommendations and extend the technology; the use of an excessively remote planning horizon over which to accumulate benefits; and failure to incorporate the costs of any lost production that might have resulted through the use of a truncated spray regimen, particularly given research results suggesting that compensation for early insect damage did not occur at high yield levels (Brook et al., 1992a,b,c).

In other situations, computer-based technology is not required in order to implement a programme of integrated pest management (e.g. Van de Fliert, 1993). The essence of the SIRATAC system had earlier been captured by Philippino researchers using a simple peg board. Many decision tools for pest management are available (Norton \& Mumford, 1993). It was far from clear that the marginal contribution of the SIRATAC technology in terms of improved routine decision-making behaviour justified the large marginal cost of continuing to maintain and update the model. There were no procedures in place to terminate the technology once its potential to facilitate the introduction of IPM had been exploited.

It was this situation that prompted the soft systems study by Macadam et al. (1990). There was little real possibility that a soft systems intervention would ameliorate the mess. The professional researchers were not committed to this kind of activity and rejected the conceptual framework on which it was based. This lack of sympathy for Soft Systems Methodology (Checkland, 1981) was based on ignorance of the problematical nature of operations research in an industrial and commercial context. Researchers were isolated, poorly informed about recent developments in systems thinking (especially the critique of hard systems and the emergence of the human-centred systems movement), excessively protective of 
their first shot at solving the problem, vulnerable to the hype of systems engineers because of the lack of a marginal perspective, and unwilling to entertain the notion that the technology had already run its course.

\section{Unwarranted escalation of organisational commitment}

The development of organisational inertia, even to the extent of escalation of commitment, has been noted in other contexts, for example, British Columbia's decision to host Expo 86 in Vancouver (Ross \& Staw, 1986), and the Shoreham nuclear power plant (Ross \& Staw, 1993). Ross \& Staw (1993) present 12 propositions on escalation. Whereas all of these are potentially applicable to this case, three are particularly pertinent:

1. The more external political forces become aligned with a project, the more difficult it will be for the initiating organisation to withdraw from the course of action. This applied to the calls for early commercialisation of SIRATAC by growers (which led to the setting up of SIRATAC Ltd); the need for SIRATAC Ltd to develop a new product, and interest by the DIT in a demonstration project (which led to the abortive development of SIRATAC Plus); and the support of SUG for a microcomputer application that incorporated the original SIRATAC models (which led to the development, and increasing complexity, of entomoLOGIC).

2. The more ambiguous and changing the economics of a project, the more difficult it will be for an organisation to extricate itself from the selected course of action. The marginal contribution of the SIRATAC model to routine pest management decisions was not critically evaluated. Indeed, it was considered as an industry standard which did not need to be justified in economic terms. It is clear that it did facilitate the introduction of IPM in the early 1980s, but these gains were short-lived because the spray recommendations could be adequately generated without the model. The sunk costs, both technical and institutional, were a source of organisational inertia, preventing rapid adaptation to a changing situation in the Australian cotton industry.

3. Escalation problems are especially likely to occur when managers venture far from their areas of expertise or when technological changes cause such major changes in an organisational context that previously learned procedures and decision checks are no longer applicable. There were no controls in place that would make SIRATAC selfterminating. There was no monitoring of the effectiveness of SIRATAC in generating improved practices, compared with other 
ways of doing things. If SIRATAC had terminated in the early 1980 s, it would have avoided many of these problematical issues. As it was, it was hijacked by technical specialists in the emerging technology of decision support and expert systems.

\section{Some specific propositions about the case study}

I would like to suggest some additional propositions to help us learn from, and move on, from the SIRATAC experience.

The sources of technological controversy surrounding SIRATAC were not unusual

Throughout the 1980s, the SIRATAC technology had become increasingly controversial and the source of serious confrontation within the Australian cotton industry. The major sources of technological controversy surrounding SIRATAC relate to the justification for spraying on threshold, what those thresholds should be, the choice of insecticide, and the choice of information technology to manage that justification. There was a research agenda to reduce pesticide use overall, and the use of particular pesticides. The information technology selected (the SIRATAC models, accessed remotely) was far from transparent and very much in the research domain. There are similarities with Rüdig's (Rüdig, 1993) description of the sources of technological controversy in the nuclear power industry. First, the subversive character of the scientific process itself; science is about seeing the world in new ways, and identifying opportunities to change it. Both nuclear power and SIRATAC were science-based technologies. Second, the impossibility of evaluating a technology under full operational conditions. This applies almost as much to agricultural DSSs as to Rüdig's example of nuclear power because of the variability of the response in different years and at different locations. Third, if the level of complexity of the technology makes it difficult to evaluate easily from the outside - again as applicable to agricultural DSSs as nuclear power because of the inaccessibility of the underlying model base.

There was an alternative technology

The implementation of the Insecticide Resistance Management (IRM) Strategy, following the discovery of resistance to pyrethroids at Emerald in early 1983, provided an alternative to SIRATAC (Cox \& Forrester, 1992). This depended on restricting the use of certain classes of insecticide to certain times of the year. The IRM is not a computer-based technology. It 
depends for its success on participation, negotiation and commitment by many sectors of the cotton industry including growers, input suppliers and researchers. It is a social technology. The returns to this technology, however, appear to have been substantial. It has not met many of the problems faced by SIRATAC. It is perceived to be an appropriate industry-level response to an industry-wide problem: the management of the stock of susceptibility in the insect population to current chemical insecticides that are valued on other grounds (cost, sclectivity, non-persistence).

The role of SIRATAC, like that of the alternative technology, was primarily social

I have argued elsewhere (Cox, 1993b) that the main function of SIRATAC was as a source of legitimation for IPM among cotton-growers and, later, for the Australian cotton industry in its long-running dispute with environmentalists who were concerned with excessive and inappropriate use of insecticides - not to support routine decision-making on pesticide selection and use. Its portrayal as a successful DSS is misleading in situations where this kind of power relationship is absent. Perhaps the illusion of its success had to be maintained for the industry to accomplish the introduction of IPM and cope with the environmental lobby. But even in this case. the particular approach used by SIRATAC (the assertion of recommended practices based on an algorithmic approach, poorly justified at the margin compared with simpler, more transparent, more empowering approaches) remains problematical.

The quality of information is important, but poorly understood I accept that knowledge is becoming more significant than either wealth or violence in shaping power relationships in society (Tofler, 1990); that knowledge is increasingly important as a factor of production in economic processes compared with land, labour and capital (Drucker, 1993); and the possibility that substituting knowledge (embodied as human capital) for natural resources might also be necessary for sustainable development, as suggested by Pearce ct al. (1989). In these situations, however, it becomes all the more important to be clear that not all knowledge is equally useful, irrespective of who is using it and how it is applied, and to develop design criteria for knowledge transformations. This point is also stressed. in at wider context, by Funtowicz \& Ravetz (1990).

The tendency for scientific knowledge to override practical knowledge impedes communication

The confrontation between episteme and techne (Marglin, 1992), and our failure to integrate these, lies at the root of these pathological R\&D 
processes. Roughly, episteme corresponds with the scientific knowledge of professional researchers; techne with the practical knowledge of practitioners (such as farmers). It is the gulf between these two systems of knowledge that we need to bridge. The development and promotion of agricultural DSSs by professional researchers (even worse, their use in an attempt to legitimate underlying $\mathrm{R} \& \mathrm{D}$ practice) is further evidence of the tendency of episteme to override techne. This is understandable because of the nature of the different worlds that scientists and farmers live in, and their differential access to technology. The increasingly urgent question is rather about how to bring these two perspectives together to facilitate the achievement of purposeful change in both.

\section{DSS technology can be used to help define quality and to capture different interpretations}

The underlying modelling skills may be used in an attempt to bring episteme and techne together: these confront each other in the context of a shared experiment. But, as Peters (1992) points out, and as shown in the SIRATAC example, it is important not to listen to customers at times. This supports Shulman's contention (Shulman, 1993) that R\&D should be neither technology-driven nor market-driven, but marketrelevant.

In my experience, the construction of agricultural DSSs, and attempts to use them as interventions in social systems in order to achieve targeted change in human behaviour, is problematical for several reasons. It reinforces the separation of professional researchers from their clients because this activity is largely conducted in isolation and in esoteric terms. It confuses different ways of looking at the world, and tries to impose a world view which (while appropriate for scientific understanding) is largely incompatible with the more pressing requirements of practitioners. In failing to recognise the scope for algorithmic compression in the formulation of practical recommendations (even if through the deconstruction of professional models), agricultural DSSs represent an abdication of professional responsibility and a failure of accountability. Agricultural DSSs have been a misapplied metaphor.

However, this is not strictly a problem peculiar to DSS technology. It is a symptom of a deeper malaise affecting communication among different stakeholder groups (research, extension, farmers): provision of a DSS becomes a substitute for communication, rather than contributing to the identification, development and realisation of novel possibilities. There is a danger that DSSs will become a whipping boy - that is not what I want. There is scope for doing things differently, and DSS technology can be part of the solution. 


\section{RE-NEGOTIATING THE CRITERIA FOR SUCCESS IN DSS DEVELOPMENT}

The process of developing agricultural DSSs in recent years has changed both the way in which agricultural science is done and the expectations of industry. But the experience has been ambiguous and can be viewed in different ways.

DSS research has been associated with the formation of systems teams which became the nucleus for state and national cooperation and who shared data and ideas. It provided a framework for the integration of research and extension (and, to a much more limited extent, grower) experience. It led to the development of operational systems for information products of other kinds, e.g. drought alert. Systems analysis, using a DSS applied to the real world, provided an honest and responsible test of the underlying science. No-one else had the courage or the stupidity to see if scientific predictions worked in the field. Our science, by itself, will not be good enough to bring about resolution or change where it is needed. But progress can be made through conflict, and conflict is sometimes necessary, especially when confronting entrenched views. DSS research has a track record of dragging these conflicts into the open, even if the DSS is destroyed in the process.

Agricultural science is not science unless it predicts, and tests its predictions. DSS research made this test explicit. If the prediction is wrong, then the model is wrong and knowledge advances. If we stop DSS research, we stop the most active test of our understanding of the behaviour of complex systems. DSS research has been a very humbling experience for science because it shows clearly where science cannot predict, and how lacking in understanding we are. DSS research brings scientists and industry together. SIRATAC was (at least in its early years) an outstanding example of contact between industry and science.

Many problems can be solved very well without DSSs, and the marginal benefit does not justify the cost of developing and maintaining them. However, in other applications, it is doubtful whether DSSs yet have sufficient resolution to be used in the way we want, for example in order to allow professional researchers to contribute to farmers' experiments (Cox et al., 1993). The one path (use of information technology in an attempt to buttress an outdated linear model of agricultural extension) is a blind alley. The other (use of DSS construction as a process tool) can offer potential for substantial payoffs because of the way it broadens the scope for shared experience and captures the synergy associated with combining perspectives. 
The construction, application, and modification of models of various kinds may help to bridge the gap between traditional systems of scientific thought and emerging systems of action (Cox et al., 1994). Professional researchers are only just beginning to explore the potential for introducing wider social arrangements within our systems modelling in order to stimulate both thought and action. But it does not follow that the researchers' models are the most effective vehicle for effecting directed change in the management of agricultural production systems. They might suggest fruitful avenues to explore, or the probable shape of response surfaces. The exploitation of such insights may best be handled in ways other than by rehearsing the representations through which they were developed. I propose working with parallel models and multiple representations, not the abolition of all modelling activities.

My main concern is not that DSS technology has failed to live up to initial expectations, but that the underlying skills in systems analysis have not been adequately exploited. The side-effects associated with the development of some significant DSS technologies have sometimes been beneficial and significant, but the opportunity to learn from these, and move on, has not been taken. It is the benefits associated with DSS development that we need to capture again and again, not the unthinking replication of artefacts that do not do anything very much. It is time to renegotiate the criteria for success in DSS research, and to begin to value DSSs as process tools rather than unwanted artefacts. Information technology, including DSSs, can make a vital contribution to help address the increasingly urgent need for business process re-engineering (Champy, 1995) in agricultural R,D\&E.

The criteria for success should not be related to the number of units of a DSS sold because, as I have argued, this is an inappropriate use of the underlying modelling skills. Rather, they should relate to the critical insights gained through improved communication of the different perspectives of researcher and farmer. The beneficial outcomes of model-based research will come from the use of DSS technology to support participatory processes to design better (more productive, more sustainable) agricultural production systems, not in the routine (and unthinking) output of the same models in an attempt to influence the behaviour of others not involved in their development.

This shifts the focus to the joint responsibility to generate, test and implement critical insights in an effective, efficient and expeditious manner, and away from the provision of mundane management tools with no particular message or computational advantage. The short life of many DSSs may then be evidence of success (if desired change has been quickly achieved), not failure. Consideration can be focussed on the timely termination of an intervention, rather than how to endure an ongoing commitment to a 
technology once it has achieved what it set out to do. The tendencies towards escalation of commitment, and to ever-increasing complexity, are curtailed. The trick is to do this while simultaneously capturing the primary benefits of participation in modelling.

\section{ACKNOWLEDGEMENTS}

Ken Brook contributed to the development of the case study. Greg McKeon, Art Shulman, Janice Jiggins, Peter Ridge, Duncan Lowes and Daniel Walker all provided helpful comments on an earlier draft.

The financial contribution of the Land and Water Resources Research and Development Corporation, the Grains Research and Development Corporation, and the Rural Industries Research and Development Corporation of Australia is acknowledged.

\section{REFERENCES}

Ackoff, R. L. \& Sasieni, M. W. (1968). Fundamentals of Operations Research. John Wiley \& Sons, New York, NY.

$\Lambda$ delman, L. (1992). Evaluating Decision Support Systems. John Wiley \& Sons. New York, NY.

Angell, I. O. \& Smithson, S. (1990). Managing information technology: a crisis of confidence? European Management Journal, 51, 27-36.

Badham, R. (1991). Machine metaphors and conspicuous production: the human-centred systems movement and the re-enchantment of technology. Science and Technology Analysis Research Programme Working Paper No. 5 , University of Wollongong.

Baecker, R. M. (ed.) (1993). Readings in Groupware and Computer-supported Cooperative Work. Assisting Human-human Collaboration. Morgan Kaufmann, San Mateo, CA.

Bennett, D. \& Macpherson, D. K. (1985). Structuring a successful modelling activity. In Agricultural Systems Research for Developing Countries: Proceedings of an International Workshop held at Hawkesbury Agricultural College Richmond, N.S.W., Australia, 12-15 May 1985, ed. J. V. Remenyi. pp. $70-6$.

Bennett, J. L. (ed.) (1983). Building Decision Support Systems. Addison-Wesley, Reading, MA.

Brook, K. D. \& Hearn, A. B. (1983). Development and implementation of SIRATAC: a computer-based cotton management system. In Computers in Agriculture, Proceedings of the Ist National Conference, University of Western Australia, pp. 222-41.

Brook, K. D. \& Hearn, A. B. (1990). The SIRATAC pest management computer program. Program content (July 1988). Technical Paper. CSIRO Division of Plant Industry, Canberra. 
Brook, K. D., Hearn, A. B. \& Kelly, C. F. (1992a). Response of cotton (Gossypium hirsutum L.) to damage by pests in Australia: 1. Pest management trials. Journal of Economic Entomology, 85, 1356-67.

Brook, K. D., Hearn, A. B. \& Kelly, C. F. (1992b). Response of cotton (Gossypium hirsutum L.) to damage by pests in Australia: 2. Manual simulation of insect damage. Journal of Economic Entomology, 85, 1368-77.

Brook, K. D., Hearn, A. B. \& Kelly, C. F. (1992c). Response of cotton (Gossypium hirsutum L.) to damage by pests in Australia: 3. Compensation for early season damage. Journal of Economic Entomology, 85, 137886.

Champy, J. (1995). Re-engineering Management. The Mandate for New Leadership. Harper Collins, New York, NY.

Checkland, P. (1981). Systems Thinking, Systems Practice. John Wiley \& Sons, Brisbane.

Collins, H. M. (1990). Artificial Experts. Social Knowledge and Intelligent Machines. MIT Press, Cambridge, MA.

Costanza, R., Wainger, L., Folke, C. \& Mäler, K.-G. (1993). Modelling complex ecological economic systems. BioScience, 438, 545-55.

Coulomb, R. M., Hearn, B., Brook, K., Jansen, B., Ashburner, N. \& Clarke, M. (1988). SIRATAC: expert decision support for cotton pest management. Information Technology Technical Report TR-FD-88-01. CSIRO Division of Information Technology, North Ryde.

Cox, P. G. (1993a). Uses and abuses of complexity in an uncertain world: implications for decision support. Proceedings Australia Pacific Extension Conference, Surfers Paradise, Queensland, Australia, October 12-14, 1993. Vol. 1, pp. 233-7.

Cox, P. G. (1993b). SIRATAC. DPI Systems Study Group Selected Papers, Vol. 1. Queensland Department of Primary Industries, Brisbane, pp. 74-6.

Cox, P. G. \& Forrester, N. W. (1992). Economics of insecticide resistance management in Heliothis armigera (Lepidoptera: Noctuidae) in Australia. Journal of Economic Entomology, 855, 1539-50.

Cox, P. G., Garside, A. L. \& McCown, R. L. (1993). Participatory design of an on-farm agronomic research program in Central Queensland. Proceedings of the 7th Australian Agronomy Conference, Adelaide, 19-24 September 1993, pp. 325-7.

Cox, P. G., Marsden, S. G., Brook, K. D., Talpaz, H. \& Hearn, A. B. (1991). Economic optimisation of Heliothis thresholds on cotton using a pest management model. Agricultural Systems, 35, 157-71.

Cox, P., Parton, K., Freebairn, D. \& Connolly, R. (1994). Economic and policy issues in effective implementation of resource conservation strategies. Paper presented at 8th International Soil Conservation Conference, December 4-8 1994, Delhi, India.

Daly, H. E. (1991). A. N. Whitehead's fallacy of misplaced concreteness: examples from economics. In Steady-state Economics, 2nd Edn, with New Essays, Ch. 17. Island Press, Washington, DC, , pp. 280-7.

Drucker, P. (1993). Post-capitalist Society. Harper Business, New York, NY.

Finlay, P. N. \& Wilson, J. M. (1991). Validation of decision support systems: recent developments and findings. Systems Practice, 46, 599-610.

Funtowicz, S. O. \& Ravetz, J. R. (1990). Uncertainty and Quality in Science for Policy. Kluwer, Dordrecht. 
Goodwin, P. \& Wright, G. (1991). Decision Analysis for Management Judgement. Wiley, Brisbane.

Hamilton, W. D., Woodruff, D. R. \& Jamieson, A. M. (1991). Role of computerbased decision aids in farm decision making and in agricultural extension. In Climatic Risk in Crop Production: Models and Management for the Semi-arid Tropics and Subtropics, eds C. Muchow \& J. A. Bellamy. CAB International, Wallingford, pp. 411-23.

Hanger, A. \& Vock, N. (1993). Supermarkets for information -- can self-service work? Proceedings Australia Pacific Extension Conference Surfers Paradise, Queensland, Australia, October 12-14, 1993, Vol. 1, pp. 223-5.

Hearn, A. B. (1987). SIRATAC: a decision support system for cotton management. Rev. Market. Agric. Econ., 352, $170-3$.

Hearn, A. B. \& Brook, K. D. (1989). A case study of the application of a knowledge-based system to cotton pest management: a tale of two technologies. AI Applications in Natural Resource Management, 33, 60-4.

Hearn, A. B., Ives, P. M., Room, P. M., Thomson, N. J. \& Wilson, L. T. (1981). Computer-based cotton pest management in Australia. Field Crops Research, 4, 321-32.

Hirschmann, A. O. (1970). Exit, Voice and Loyalty. Harvard University Press, Cambridge, MA.

Hofstede, G. J. (1992). Modesty in Modelling: On the Applicability of Interactive Planning Systems with a Case Study in Pot Plant Cultivation. Doctoral Dissertation. Agricultural University, Department of Computer Science. Wageningen.

Ives, P. M. \& Hearn, A. B. (1987). The SIRATAC system for cotton pest management in Australia. In Crop Loss Assessment and Pest Management, ed. P. S. Teng, Ch. 25, APS Press, Minnesota. pp. 251-68.

Ives, P. M., Wilson, L. T., Cull, P. O., Palmer, W. A., Haywood, C., Thomson, N. J., Hearn, A. B. \& Wilson, A. G. L. (1984). Field use of SIRATAC: an Australian computer-based pest management system for cotton. Prot. Ecol. 6, $1-21$.

Johnston, B., Healy, T., I'ons, J. \& McGregor, M. (1992). Rural research - the pay-off. The returns from research undertaken by the CSIRO Institute of Plant Production and Processing. Occasional Paper No. 7. CSIRO, Canberra.

Kingwell, R. S. \& Pannell, D. J. (eds) (1986). MIDAS, a Bioeconomic Model of a Dryland Farming System. PUDOC, Wageningen.

Konikow, L. F. \& Bredehoeft, J. D. (1992). Groundwater models cannot be validated. Advances in Water Resources, 15, 75-83.

Lamb, R. (1993). Designs on life. New Scientist, 1897, 37-40.

LWR RDC (1993). Information Exchange. A report commissioned by Australia's rural research and development corporations. Land and Water Resources Research and Development Corporation, Canberra.

Leeuwis, C. (1993). Of Computers, Myths and Modelling. The Social Construction of Diversity, Knowledge, Information and Communication Technologies in Dutch Horticulture and Agricultural Extension. Wageningen Studies in Sociology 36. Agricultural University, Wageningen.

Macadam, R. (1988). SIRATAC's role in the cotton industry. The Australian Cotton Grower, 93, 6-8. 
Macadam, R., Britton, I., Russell, D., Potts, W., Baillie, B. \& Shaw, A. (1990). The use of soft systems methodology to improve the adoption by Australian cotton growers of the Siratac computer-based crop management system. Agricultural Systems, 34, 1-14.

Macpherson, D. K. \& Grant, I. W. (1989). Integrating simulation and policy argument. Proceedings of the 8th Biennial Conference of the Simulation Society of Australia, 25-27 September 1989, pp. 331-6. Australia National University, Canberra.

Marglin, S. A. (1992). Farmers, seedsmen, and scientists: systems of agriculture and systems of knowledge. Unpublished paper.

Maxwell, J. A. \& Randall, A. (1989). Ecological economic modelling in a pluralistic, participatory society. Ecological Economics, 1, 233-49.

McKewen, L., Madden, W., Klinge, S. \& Nash, G. (1994). Management tools for integrated pest management - entomoLOGIC's role. Proceedings of the 7 th Australian Cotton Conference, Broadbeach, 1994, pp. 155-69.

McKinion, J. M., Reddy, K. R. \& Hodges, H. F. (1992). Alleviation of global climate change impact via simulation-based decision support systems in agriculture. World Resource Review, 44, 406-18.

Monteith, J. L. (1981). Epilogue: themes and variations. Plant and Soil, 58, $305-9$.

Norton, G. A. \& Mumford, J. D. (1993). Decision Tools for Pest Management. CAB International, Wallingford.

O'Keeffe, M. (1992). A qualitative project into the adoption of pasture research and the potential for GRAZFEED. Report prepared for the CSIRO Institute of Plant Production and Processing. Australian Agribusiness Research Unit, David Syme Faculty of Business, Monash University, Melbourne.

Oreskes, N., Shrader-Frechette, K. \& Belitz, K. (1994). Verification, validation, and confirmation of numerical models in the earth sciences. Science, 263, 641-6.

Pearce, D., Markandya, A. \& Barbier, E. B. (1989). Blueprint for a Green Economy. Earthscan Publications, London.

Peters, T. (1992). Liberation Management. Necessary Disorganization for the Nanosecond Nineties. Macmillan, London.

Philip, J. R. (1991). Soils, natural science and models. Soil Science, 1511, 91-8.

Reynolds, J. (1993). Computer Software for Agriculture, 7th Edn. NSW Agriculture, East Maitland.

Room, P. M. (1979). A prototype 'on-line' system for management of cotton pests in the Namoi Valley, New South Wales. Prot. Ecol., 1, 245-64.

Ross, J. \& Staw, B. M. (1986). Expo 86: an escalation prototype. Administrative Science Quarterly, 31, 274-97.

Ross, J. \& Staw, B. M. (1993). Organizational escalation and exit: lessons from the Shoreham nuclear power plant. Academy of Management Journal, 364, 701-32.

Rüdig, W. (1993). Sources of technological controversy. Proximity to or alienation from technology. In The Politics of Expert Advice. Creating, Using and Manipulating Scientific Knowledge for Public Policy, eds A. Barker \& B. G. Peters, Ch. 2. Edinburgh University Press, Edinburgh, pp. 17-32.

Ryle, G. (1963). The Concept of Mind. Penguin, Harmondsworth.

Sage, A. P. (1991). Decision Support Systems Engineering. John Wiley \& Sons, New York, NY. 
Schmidt, D. J. (1994). Introducing crop simulation technology using soft systems methodology: some issues in agricultural communication. Unpublished Masters Thesis. Queensland University of Technology, Brisbane.

Seligman, N. G. (1990). The crop model record: promise or poor show? In Theoretical Production Ecology: Reflections and Prospects, eds R. Rabbinge, J. Goudriaan, H. van Keulen, F. W. T. Penning de Vries \& H. H. van Laar, Ch. 14. PUDOC, Wageningen, pp. 249-63.

Senge, P. M., Roberts, C., Ross, R. B., Smith, B. J. \& Kleiner, A. (1994). The Fifth Discipline Fieldbook. Strategies and Tools for Building a Learning Organization. Nicholas Brealey Publishing, London.

Shulman, A. (1993). RDE, ERD, or RED? Scrambling for power and effectiveness. Proceedings Australia-Pacific Extension Conference, Vol. 1. pp. 52-6.

Stapper, M. (1993). The application and use of information technology on farms: applications in search of users or users in search of applications. Paper presented at the Tasmanian Zone of the Australian Institute of Agricultural Science National Conference.

Tofler, A. (1990). Powershift. Knowledge, Wealth and Violence at the Edge of the 21 st Century. Bantam Books, New York, NY.

Turban, E. (1993). Decision Support and Expert Systems. Management Support Systems. Macmillan, New York, NY.

Van de Fliert, E. (1993). Integrated pest management. Farmer field schools generate sustainable practices: a case study in Central Java evaluating IPM training. WU Papers 93-3. Agricultural University, Wageningen.

Whitehead, A. N. (1929). Process and Reality. Harper Brothers, New York, NY.

Willcocks, L. (ed.) (1994). Information Management. The Evaluation of Information Systems Investments. Chapman \& Hall, London. 